\section{SUCKING AND SWALLOWING IN INFANTS}

BY

\section{J. R. T. COLLEY, M.B., B.S., B.Sc.} Junior Research Registrar

AND

\section{B. CREAMER, M.D., M.R.C.P. Lecturer in Medicine}

From St. Thomas's Hospital Medical School, London

It is firmly embedded in tradition that infants obtain their milk by sucking. Objective evidence for this has been presented by workers who have recorded negative pressures in the mouth during feeding (Gunther, 1945 ; Hytten, 1951). However, there is a large body of opinion which maintains that infants express milk from the teat by a squeezing process. Support for this view has come from a recent cineradiographic study of bottlefeeding (Ardran et al., 1958).

The present study was designed to reinvestigate this problem and also to define the swallowing mechanism of infants. The technique used, that of recording the intraluminal pressures of the pharynx and oesophagus, has already been extensively practised in the investigation of the adult swallowing mechanisms. For comparison with the present observations there are many recorded data on the adult pharyngo-oesophageal junction (Fyke and Code, 1955), oesophagus (Butin et al., 1953 ; Dornhorst et al., 1954), and gastro-oesophageal junction (Sanchez et al., 1953; Fyke et al., 1956).

\section{Methods}

The intraluminal pressures were recorded indirectly through open-tipped, water-filled "polythene" tubes attached to Hansen capacitance manometers. The tubes were of $1 \mathrm{~mm}$. external diameter and $0.5 \mathrm{~mm}$. internal diameter. Three tubes were used for simultaneous recording at different sites and were arranged so that either all three were fastened together with recording holes spaced at intervals of 2 to $4 \mathrm{~cm}$. or two tubes were fastened together and the third was free to be placed at an independent site, usually in the mouth (Fig. 1).

Recordings were made during feeding by using a boatshaped bottle (volume $250 \mathrm{ml}$.) with an opening at each end closed by a rubber teat. The tubes were passed through the bottle and teats via a central hole. A variety of milk flows were produced by punching additional holes in the teats. The flow rates were not accurately measured during each feed, but the teats were divided into three groups: high-flow teats passing over $36 \mathrm{ml}$. of milk a minute, moderate-flow teats passing $28-36 \mathrm{ml}$. a minute, and lowflow teats passing up to $28 \mathrm{ml}$. a minute on inverting the bottle. Maw's " anticolic" rubber teats were used in all experiments, the bulb diameter being $15 \mathrm{~mm}$. and waist diameter $11 \mathrm{~mm}$.

The tubes were passed through the mouth into the oesophagus and the infant began sucking immediately. During

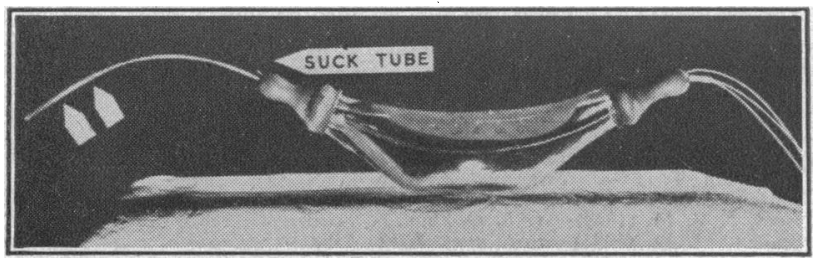

Fig. 1.-Feeding-bottle and teats, showing polythene tubes in position. Two tubes are fastened together, the recording holes
indicated by arrows, and the third tube is positioned to record from the suck area. the recording the tubes were withdrawn in steps of 0.25 to $2 \mathrm{~cm}$. from the stomach up the oesophagus and through the pharynx. Recordings were also made immediately distal to the teat and within the teat.

Fourteen normal infants who were convalescent from minor disorders were examined. Their ages ranged from 5 weeks to 7 months. All were normally bottle-fed and recordings were made at the usual feeding-time with their customary volume and type of artificial milk.

\section{Results}

Sucking

Repetitive, negative-pressure swings were recorded from the mouth during sucking (Fig. 2). The magnitude of the pressure drop with each suck appeared to depend on the ease with which milk flowed from the teat. With low-flow teats average negative pressures of 120 to $230 \mathrm{~cm}$. of water were recorded. As the milk flow increased the negative pressures tended to become less; moderate-flow teats were associated with average negative pressures of $60-160 \mathrm{~cm}$. of water. Eventually, by increasing the milk flow still further, a point was reached when the infant ceased to suck. The pressures attained were independent of the age or size of the infants; the highest negative pressure recorded was $250 \mathrm{~cm}$. of water in an infant 9 weeks old and using a teat with a very low flow.

Sucking was usually regular and completely independent of respiration. When the milk flows were moderate the rate of sucking varied from 50 to 70 a minute, and was usually maintained at a constant rate a n d amplitude throughout the feed. With low milk flows sucking usually occurred in bursts of 10 to 15 sucks with fast sucking rates up to 130 a minute. The duration of each negative-pres-

sure swing varied with the rate; at high sucking rates the duration was between 0.3 and 0.5 second, while with lower sucking rates the duration was up to 0.7 second. In most instances the pressure in the mouth returned to the baseline after each suck (Fig. 2), but in some infants a negative level was sustained between sucks (Fig. 3). This varied from 20 to $60 \mathrm{~cm}$. of water.

The area in which these negative pressures were present was mapped out by withdrawing a recording tube at 0.25 $\mathrm{cm}$. intervals from the pharynx back into the teat. In nine infants in whom this was done the negative pressures were present only within a distance of $1 \mathrm{~cm}$. distal to the tip of the teat as it lay naturally in the mouth. By withdrawing a tube along the outside of the teat the area of negative pressure was demonstrated up to the waist of the teat. 
Pressures measured immediately within the tip of the teat showed a regular small swing. Each suck is preceded by a biting movement of the jaws, and this is associated with a small rise in pressure within the teat of 5 to $7 \mathrm{~cm}$. of water. Following this there is a small fall in pressure of 5 to $7 \mathrm{~cm}$. of water during the suck.

\section{Swallowing}

Pharynx.-Swallowing produced a brief rise in pressure that travelled swiftly through the pharynx in a peristaltic

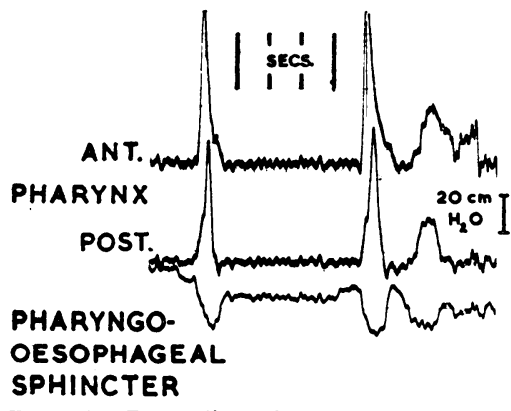

Fig. 4.-Recording from the pharynx (upper two traces) and pharyngooesophageal sphincter during two
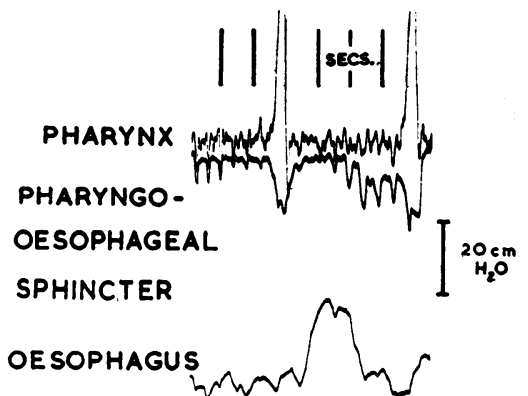

Fig. 5.-Recording from the pharynx, pharyngo-oesophageal sphincter, and oesophagus. Note the sequence of pharyngeal contraction, relaxation of the sphincter, and oesophageal peristaltic wave.

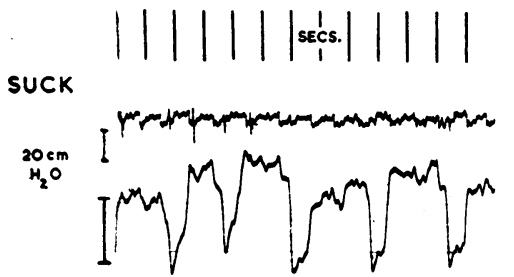

PHARYNGO-OESOPHAGEAL SPHINCTER

FIG. 6.-Recording from the mouth and pharyngo-oesophageal sphincter using a high milk flow. Note the absence of sucking and the repetitive relaxations of the sphincter.

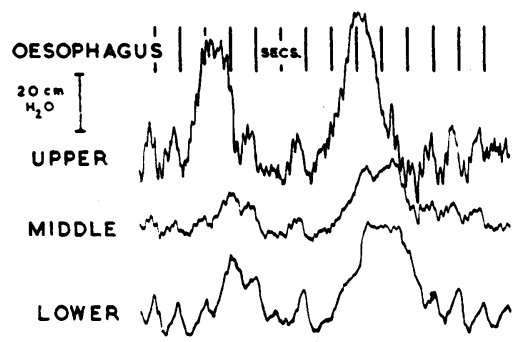

FIG. 7.-Recording from upper, middle, and lower oesophagus showing two peristaltic waves. second, being swifter in the lower half of the oesophagus than the upper half. With repetitive swallowing a wave was recorded for only a few centimetres below the pharyngooesophageal sphincter and was absent throughout the rest of the oesophagus.

Gastro-oesophageal Junction.-This appeared to be an extremely localized area. Detailed observations were technically impossible, as the infants did not cease from swallowing long enough to permit recordings of resting pressure. The point of reversal of the respiratory pressure swing from an intra-abdominal to an intrathoracic pattern could be recognized. The peristaltic wave in this area differed from the oesophageal form in being prolonged, and lasted up to 10 seconds. If a second swallow was initiated while this prolonged pressure rise was present the pressure at once fell to the previous level.

\section{Discussion}

The present observations leave no doubt that infants can suck vigorously and that this is intensified as milk becomes harder to obtain. By contrast, the pressure changes within the teat are trivial, and this suggests that, in these experiments, squeezing the teat by the jaws and tongue played little part in extracting milk. However, the physical conditions in using a double-ended bottle may be different from a single-ended one, while breast-feeding is further complicated by additional factors, including the "draught" reflex. Therefore the present findings cannot be assumed to hold good in all conditions.

Ardran et al. (1958), in a cineradiographic study of bottle feeding, described the movements of the jaws and tongue. Initially the jaws move together, gripping the teat, while the tongue begins to indent the inferior aspect of the teat. The tongue then moves backwards so that the outline of the teat is flattened, and during this time milk passes into the mouth. These appearances were interpreted as a squeezing process expressing milk from the teat. Our observations do not support this, but combined pressure and cineradiographic observations would be necessary to define this point. The backward movement of the tongue within the mouth is most probably the method of producing the negative sucking pressures, similar to withdrawing a piston in an airtight syringe.

The pressures obtained during swallowing show an identical pattern to those recorded in adults. In particular the magnitude and timing of the pressure changes correspond almost exactly to the adult data. The technique is simple and well tolerated, and should prove useful in investigating difficulty in feeding and swallowing in this age group.

\section{Summary}

Pressures in the mouth, pharynx, and oesophagus have been measured in 14 infants during bottle-feeding. Sucking is accompanied by marked negative pressures in the mouth, while pressure changes within the teat are small. This has been interpreted that sucking, rather than squeezing the teat, is the more important action in obtaining milk. The pressures recorded during swallowing show an identical pattern in the pharynx, oesophagus, and junctional areas to that recorded in adults.

We are grateful to Dr. J. Forest Smith and Dr. B. D. R. Wilson for allowing us to examine infants under their care.

\section{REFERENCES}

Ardran, G. M., Kemn. F. H., and Lind, J. (1958). Brit. J. Radiol., 31, 11. Butin, J. W., Olsen, A. M., Moresch, H. J., and Code, C. F. (1953) Gastroenterology, 23, 278

Dornhorst, A. C., Hatrison, K., and Pierce, J. W. (1954). Lancet, 1, 695. Fyke, F. E., and Code, C. F. (1955). Gastroenterology, 29, 24

Fyk, F. and Schlegel, J. F. (1956). Gastroenterologia (Basel), 86, 135.

Gunther, M. (1945). Lancet, 2, 590 .

Hytten, F. E. (1951). Arch. Dis. Childh., 26, 477. (1953). Gastroenterology 25, 321.
anchez, 